\title{
Social Cognition in the Frontal Variant of Alzheimer's Disease: A Case
}

\section{study}

Harmony Duclos ${ }^{\mathrm{a}}$, Vincent de La Sayette ${ }^{\mathrm{a}}$, Anne-Laure Bonnet ${ }^{\mathrm{a}}$, Armelle Viard ${ }^{\mathrm{a}}$, Francis

Eustache $^{\mathrm{a}}$, Béatrice Desgranges ${ }^{\mathrm{a}}$ and Mickaël Laisney ${ }^{\mathrm{a}^{*}}$

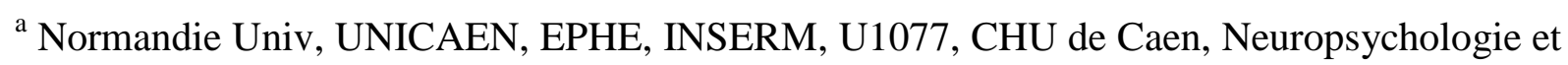
Imagerie de la Mémoire Humaine, 14000 Caen, France

Running title : Social cognition in fv-AD

* Corresponding author. Laboratoire de Neuropsychologie et Imagerie de la Mémoire Humaine, Normandie Univ, UNICAEN, EPHE, INSERM, U1077, Pôle des Formations et de Recherche en Santé, 2 Rue des Rochambelles, F-14032 CAEN Cedex CS 14032, France. Email: mickael.laisney@inserm.fr; Tel: +332 315683 93; Fax +332 31568391. 


\begin{abstract}
Although frontal presentations of Alzheimer's disease (fv-AD) have already been described in the literature, we still know little about patients' social cognitive abilities, especially their theory of mind (ToM). We report the case of FT, a 61-year-old woman who was diagnosed with fv-AD. Two assessments of social cognition, using a false-belief task, the Reading the Mind in the Eyes test, and a task probing knowledge of social norms, were performed one year apart. FT exhibited cognitive ToM and social knowledge deficits from the onset. Affective ToM was initially preserved, but deteriorated as the disease progressed.
\end{abstract}

Keywords: Alzheimer disease, Behavioral Symptoms, Theory of Mind, Social Norms 


\section{Introduction}

Several social cognition disorders, notably theory of mind (ToM) disturbances, have been described even in the early stages of the behavioral variant of frontotemporal dementia (bvFTD) [1,2] and Alzheimer's disease (AD) [3,4]. Bertoux et al. [3] suggested that assessing social cognition might help to distinguish bv-FTD patients from those with typical AD, whose social cognition deficits appear at a more advanced stage of the disease $[5,6]$. Executive and frontal variants of AD (fv-AD) have also been described [7], and were included in the AD diagnostic criteria [8]. Using biomarkers like cerebrospinal fluid (CSF) and posterior and/or frontal cortical atrophy, it is now possible to establish a diagnosis of fv-AD in vivo $[9,10]$. Little is known about the social cognition profile of patients with fv-AD. To our knowledge, there has been only one study, involving five patients. This study reported pathological scores on an abbreviated version of the Social cognition and Emotional Assessment [11], but shed no light on the processes of social cognition [12]. Social cognition is an umbrella term used to cover different processes, from emotion recognition to social knowledge and ToM. Here, we report the case of a patient diagnosed with fv-AD who exhibited social cognition disturbances.

\section{Methods}

\section{Case report}

FT, a right-handed woman, had a high sociocultural level, with 16 years of formal education. She had now retired, after working as an accountant for 20 years. There was no known family history of neurodegenerative disease. Aged 60, FT consulted for the first time in May 2013. During the interview, she stated that she had no problems with daily life activities, but described feelings of sadness and a lack of motivation. Her head sometimes felt empty, and she had trouble finding her words. These difficulties had resulted in voluntary social 
withdrawal. A standard neuropsychological examination failed to reveal any cognitive difficulties and complaint was linked to a depressed mood. No anti-depressant treatment was started.

In January 2014, FT complained of memory and motivation difficulties. A standard neuropsychological examination revealed apparent memory disorders and a dysexecutive syndrome (see Supplementary Data). A detailed interview with her family highlighted behavioral symptoms that had been progressing since 2010. FT met four of the five behavioral criteria for bv-FTD [13]: 1) disinhibition, characterized by loss of social behavior and compulsive purchases; 2) apathy, reflected in lack of motivation and activity restriction; 3) lack of empathy manifesting itself in social indifference and obtundation; and 4) obsessive-compulsive behavior in the form of ordering/arranging and hoarding. The neurological examination was normal, but a standard clinical brain MRI revealed frontal atrophy. CSF biomarkers collected by lumbar puncture were in favor of probable AD, with a low level of $\mathrm{A} \beta_{42}$ (718; cut-off: $700 \mathrm{pg} / \mathrm{ml}$ ), high levels of total tau (837; cut-off: $500 \mathrm{pg} / \mathrm{ml}$ ) and tau phosphorylated at threonine 181 (97; cut-off: 50pg/ml) and an Innotest ${ }^{\circledR}$ Amyloid Tau Index of $A \beta_{42} / 240+1.18$ tau $(0.58$; cut-off: <0.8) [14]. FT gave her written consent to participate in a study on social cognition involving neuroanatomical and neuropsychological examinations.

\section{Neuroanatomical examination}

An anatomical MRI was performed in January 2015. Voxel-based morphometry analyses revealed significant bilateral volume loss in posterior cingulate cortex, temporoparietal junction, lateral medial temporal and middle frontal cortices (Fig. 1) (for details on the procedure, see Supplementary Data). 


\section{Social cognition assessment}

Social cognition assessments were performed in December 2014 (T1) and December 2015 (T2). Cognitive ToM abilities were investigated using the ToM-15 [15], a first- and second-order falsebelief task comprising 15 short comic-strip stories. These stories were accompanied by a comprehension question. We computed ToM and comprehension scores (/15 each). Affective ToM abilities were assessed using a French adaptation of the Reading the Mind in the Eyes (RME) test [16], which requires inferences of emotional mental states (basic or complex emotions) to be drawn from 20 photographs of pairs of eyes of a single person. We computed both basic and complex emotion scores (/10 each). Social norm knowledge (SNK) was assessed using an original task composed of 44 drawings depicting characters involved in activities. In half the items, one of the characters failed to comply with a normal social rule (e.g., not leaving one's place to a pregnant woman waiting in line at the supermarket/leaving open the toilet's door while peeing). The other 22 items were control situations (e.g., not leaving one's place to a women waiting in line at the post office/leaving open the bathroom's door while washing one's hands). Participants first had to detect situations with a transgression, after which they had to identify the character committing a fault and then justify their response. We collected a detection score (/22), a false-alarm score (/22) (i.e., situations wrongly identified as involving a transgression) and a justification score (/22). Behavioral disorders were examined with the Frontal Behavioral Inventory (FBI) [18].

\section{Statistical analyses}

FT's social cognition scores were compared with those of 20 healthy controls (HC) matched for age (63.3 \pm 6.6 years) and formal education (12.2 \pm 3.1 years). Modified $t$ tests (19 degrees of freedom, one-tailed) [19] were used to compare FT's scores with those of HC, and Procock tests [20] were used to compare FT's scores between T1 and T2. 


\section{Results}

The social cognition performances of FT and HC are summarized in Table 1. At T1, FT's ToM-15 score was significantly lower than the mean HC score $\left(t_{19}=-3.94, p=.0009\right)$, but her comprehension was not impaired $\left(t_{19}=-0.37, p=.72\right)$. FT's score for basic emotions $\left(t_{19}=-\right.$ $+0.59, p=.56$ ) was equivalent to that of $\mathrm{HC}$, while her score for complex emotions was significantly higher $\left(t_{19}=-+2.04, p=.05\right)$. For SNK, both her detection and justification scores $\left(t_{19}=-3.79, p=.001\right.$ and $\left.t_{19}=-6.23, p=.0001\right)$ were significantly lower than those of $\mathrm{HC}$, whereas the number of false alarms did not differ significantly. FT's total FBI score corresponded to the FTD profile of behavioral disturbances (cut-off score $=27$ for behavioral disturbances).

One year later, FT displayed the same profile of performances for ToM-15 and SNK. By contrast, her RME scores for both basic and complex emotions were impaired, compared with $\mathrm{HC}\left(t_{19}=-2.10, p=.04\right.$ and $\left.t_{19}=3.19, p=.004\right)$. FT's RME score was significantly lower at T2 than at $\mathrm{T} 1 \quad(z=-2.21)$. However, she exhibited fewer behavioral disturbances than at $\mathrm{T} 1$. Scores for the global cognitive scale (Montreal Cognitive Assessment) were similar for both assessments $(\mathrm{z}=0.16)$.

\section{Discussion}

This is the first detailed description of the social cognition profile of a patient with fv-AD. Consistent with the diagnosis of fv-AD, FT's atrophy corresponded to that of patients with behavioral/dysexecutive AD described in a recent neuropathological group study [10]. Some authors argued that ToM impairment of $\mathrm{AD}$ patients is the consequence of a general cognitive decline [1]. However, group studies of moderate AD patients also showed that ToM disturbances cannot been totally explained by a general cognitive deterioration [6]. As relationships between cognitive ToM and inhibition [21,22] or memory [23] were reported in 
AD and bv-FTD, FT's cognitive ToM impairment could be partly explained by other cognitive deficits. On the first assessment FT had a dysexecutive profile but preserved visual memory performance and, especially, cognitive ToM impairment without comprehension disorder. LeBouc et al. [24] reported a deficit in inhibiting self-perspective related to hypometabolism of the dorsolateral prefrontal cortex in bv-FTD, but impaired creation of representations related to hypometabolism of the temporoparietal junction in AD. FT also presented atrophy of the precuneus, the posterior cingulate and retrosplenial cortices, which are related to ToM processes [25]. All of these structures were affected in FT's case, which could account for the extent of her cognitive ToM disorders. Interestingly, affective ToM of FT appeared to be more preserved than cognitive ToM at the onset. Although the RME test is open to criticism, it has a good validity [26] and authors using it reported that affective ToM disorders are the first symptoms reported in bv-FTD [27] in contrast to typical AD [27,3]. As AD pathology progressed, affective ToM appears, possibly due to the degeneration of structures involved in emotional processing systems [29].

FT had difficulty detecting social transgressions suggesting a loss of social knowledge, whereas preserved performances for this ability were reported for AD patients on a simple questionnaire [30]. She also used social rules incorrectly as half of her justifications were inappropriate. Her deficits can be attributed either to anterior temporal atrophy, which correlates with loss of social semantic knowledge [30] or to frontal atrophy related to impaired social reasoning [31].

Differential diagnosis between bv-FTD and AD is sometimes complex, given that $80 \%$ of patients with fv-AD meet the diagnostic criteria for possible bv-FTD [10], like FT who displayed the same FBI profile as bv-FTD patients. Overall, the present case study highlights the presence of social cognition disturbances in a patient with $\mathrm{fv}-\mathrm{AD}$, suggests that affective ToM could contribute to the differential diagnosis of fv-AD and underlines the need of tasks 
with normative data assessing social cognition. The nature of the processes underpinning these deficits and the evolution of the disturbances needs to be specified with group studies, comparing fv-AD patients with bv-FTD or AD patients.

\section{Acknowledgments}

This research was supported by the French Ministry of Health (PHRC, ID-RCB: 2011A00681-40). The authors declare no conflicts of interest. We would like to thank M. Caillaud for her help with data collection and E. Portier for having editing the manuscript in fluent academic English. 


\section{Bibliography}

[1] Gregory C, Lough S, Stone V, Erzinclioglu S, Martin L, Baron-Cohen S, Hodges JR (2002) Theory of mind in patients with frontal variant frontotemporal dementia and Alzheimer's disease: theoretical and practical implications. Brain J. Neurol. 125, 752764.

[2] Henry JD, Phillips LH, von Hippel C (2014) A meta-analytic review of theory of mind difficulties in behavioural-variant frontotemporal dementia. Neuropsychologia 56, 5362.

[3] Kemp J, Després O, Sellal F, Dufour A (2012) Theory of Mind in normal ageing and neurodegenerative pathologies. Ageing Res. Rev. 11, 199-219.

[4] Gaudreau G, Monetta L, Macoir J, Poulin S, Laforce R, Hudon C (2015) Mental State Inferences Abilities Contribution to Verbal Irony Comprehension in Older Adults with Mild Cognitive Impairment. Behav. Neurol. 2015, 685613.

[5] Freedman M, Binns MA, Black SE, Murphy C, Stuss DT (2013) Theory of mind and recognition of facial emotion in dementia: challenge to current concepts. Alzheimer Dis. Assoc. Disord. 27, 56-61.

[6] Laisney M, Bon L, Guiziou C, Daluzeau N, Eustache F, Desgranges B (2013) Cognitive and affective Theory of Mind in mild to moderate Alzheimer's disease. $J$. Neuropsychol. 7, 107-120.

[7] Johnson JK, Head E, Kim R, Starr A, Cotman CW (1999) Clinical and pathological evidence for a frontal variant of Alzheimer disease. Arch. Neurol. 56, 1233-1239.

[8] McKhann GM, Knopman DS, Chertkow H, Hyman BT, Jack CR Jr, Kawas CH, Klunk WE, Koroshetz WJ, Manly JJ, Mayeux R, Mohs RC, Morris JC, Rossor MN, Scheltens P, Carrillo MC, Thies B, Weintraub S, Phelps CH (2011) The diagnosis of dementia due to Alzheimer's disease: recommendations from the National Institute on AgingAlzheimer's Association workgroups on diagnostic guidelines for Alzheimer's disease. Alzheimers Dement. J. Alzheimers Assoc. 7, 263-269.

[9] de Souza LC, Lamari F, Belliard S, Jardel C, Houillier C, De Paz R, Dubois B, Sarazin M (2011) Cerebrospinal fluid biomarkers in the differential diagnosis of Alzheimer's disease from other cortical dementias. J. Neurol. Neurosurg. Psychiatry 82, 240-246.

[10] Ossenkoppele R, Pijnenburg YAL, Perry DC, Cohn-Sheehy BI, Scheltens NME, Vogel JW, Kramer JH, van der Vlies AE, Joie RL, Rosen HJ, van der Flier WM, Grinberg LT, Rozemuller AJ, Huang EJ, van Berckel BNM, Miller BL, Barkhof F, Jagust WJ, Scheltens P, Seeley WW, Rabinovici GD (2015) The behavioural/dysexecutive variant of Alzheimer's disease: clinical, neuroimaging and pathological features. Brain J. Neurol. 138, 2732-2749.

[11] Bertoux M, Delavest M, de Souza LC, Funkiewiez A, Lépine J-P, Fossati P, Dubois B, Sarazin M (2012) Social Cognition and Emotional Assessment differentiates frontotemporal dementia from depression. J. Neurol. Neurosurg. Psychiatry 83, 411416.

[12] de Souza L, Bertoux M, Funkiewiez A, Samri D, Azuar C, Habert M-O, Lamari F, Sarazin M, Dubois B (2013) Frontal presentations of Alzheimer's disease: A series of people with biological evidence by CSF biomarkers. Alzheimers Dement. 9, P367.

[13] Rascovsky K, Hodges JR, Knopman D, Mendez MF, Kramer JH, Neuhaus J, van Swieten JC, Seelaar H, Dopper EGP, Onyike CU, Hillis AE, Josephs KA, Boeve BF, Kertesz A, Seeley WW, Rankin KP, Johnson JK, Gorno-Tempini M-L, Rosen H, 
Prioleau-Latham CE, Lee A, Kipps CM, Lillo P, Piguet O, Rohrer JD, Rossor MN, Warren JD, Fox NC, Galasko D, Salmon DP, Black SE, Mesulam M, Weintraub S, Dickerson BC, Diehl-Schmid J, Pasquier F, Deramecourt V, Lebert F, Pijnenburg Y, Chow TW, Manes F, Grafman J, Cappa SF, Freedman M, Grossman M, Miller BL (2011) Sensitivity of revised diagnostic criteria for the behavioural variant of frontotemporal dementia. Brain J. Neurol. 134, 2456-2477.

[14] Vanderstichele H, De Vreese K, Blennow K, Andreasen N, Sindic C, Ivanoiu A, Hampel H, Bürger K, Parnetti L, Lanari A, Padovani A, DiLuca M, Bläser M, Olsson AO, Pottel H, Hulstaert F, Vanmechelen E (2006) Analytical performance and clinical utility of the INNOTEST PHOSPHO-TAU181P assay for discrimination between Alzheimer's disease and dementia with Lewy bodies. Clin. Chem. Lab. Med. 44, 14721480.

[15] Desgranges B, Laisney M, Bon L, Duval C, Mondou A, Bejanin A, Fliss R, Beaunieux H, Eustache F, Muckle G (2012) TOM-15: Une épreuve de fausses croyances pour évaluer la théorie de l'esprit cognitive. Rev. Neuropsychol. Volume 4, 216-220.

[16] Baron-Cohen S, Wheelwright S, Jolliffe T (1997) Is There a "Language of the Eyes"? Evidence from Normal Adults, and Adults with Autism or Asperger Syndrome. Vis. Cogn. 4, 311.

[17] Baron-Cohen S, Wheelwright S, Hill J, Raste Y, Plumb I (2001) The "Reading the Mind in the Eyes" Test revised version: a study with normal adults, and adults with Asperger syndrome or high-functioning autism. J. Child Psychol. Psychiatry 42, 241251.

[18] Kertesz A, Davidson W, Fox H (1997) Frontal behavioral inventory: Diagnostic criteria for frontal lobe dementia. In Canadian journal of neurological sciences Canadian Journal of Neurological Sciences, pp. 29-36.

[19] Crawford JR, Howell DC, Garthwaite PH (1998) Payne and Jones revisited: estimating the abnormality of test score differences using a modified paired samples t test. J. Clin. Exp. Neuropsychol. 20, 898-905.

[20] Pocock SJ (2006) The simplest statistical test: how to check for a difference between treatments. BMJ 332, 1256-1258.

[21] Fliss R, Le Gall D, Etcharry-Bouyx F, Chauviré V, Desgranges B, Allain P (2016) Theory of Mind and social reserve: Alternative hypothesis of progressive Theory of Mind decay during different stages of Alzheimer's disease. Soc. Neurosci. 11, 409423.

[22] Lough S, Kipps CM, Treise C, Watson P, Blair JR, Hodges JR (2006) Social reasoning, emotion and empathy in frontotemporal dementia. Neuropsychologia 44, 950-958.

[23] Castelli I, Pini A, Alberoni M, Liverta-Sempio O, Baglio F, Massaro D, Marchetti A, Nemni R (2011) Mapping levels of theory of mind in Alzheimer's disease: a preliminary study. Aging Ment. Health 15, 157-168.

[24] Le Bouc R, Lenfant P, Delbeuck X, Ravasi L, Lebert F, Semah F, Pasquier F (2012) My belief or yours? Differential theory of mind deficits in frontotemporal dementia and Alzheimer's disease. Brain J. Neurol. 135, 3026-3038.

[25] Abu-Akel A, Shamay-Tsoory S (2011) Neuroanatomical and neurochemical bases of theory of mind. Neuropsychologia 49, 2971-2984.

[26] Olderbak S, Wilhelm O, Olaru G, Geiger M, Brenneman MW, Roberts RD (2015) A psychometric analysis of the reading the mind in the eyes test: toward a brief form for research and applied settings. Front. Psychol. 6, 1503.

[27] Poletti M, Enrici I, Adenzato M (2012) Cognitive and affective Theory of Mind in neurodegenerative diseases: neuropsychological, neuroanatomical and neurochemical levels. Neurosci. Biobehav. Rev. 36, 2147-2164. 
[28] Bertoux M, de Souza LC, Sarazin M, Funkiewiez A, Dubois B, Hornberger M (2014) How Preserved is Emotion Recognition in Alzheimer Disease Compared With Behavioral Variant Frontotemporal Dementia? Alzheimer Dis. Assoc. Disord.

[29] Lavenu I, Pasquier F (2005) Perception of emotion on faces in frontotemporal dementia and Alzheimer's disease: a longitudinal study. Dement. Geriatr. Cogn. Disord. 19, 3741.

[30] Panchal H, Paholpak P, Lee G, Carr A, Barsuglia JP, Mather M, Jimenez E, Mendez MF (2015) Neuropsychological and Neuroanatomical Correlates of the Social Norms Questionnaire in Frontotemporal Dementia Versus Alzheimer's Disease. Am. J. Alzheimers Dis. Other Demen.

[31] Grossman M, Eslinger PJ, Troiani V, Anderson C, Avants B, Gee JC, McMillan C, Massimo L, Khan A, Antani S (2010) The role of ventral medial prefrontal cortex in social decisions: converging evidence from fMRI and frontotemporal lobar degeneration. Neuropsychologia 48, 3505-3512. 


\section{Tables}

Table 1. Social cognition data for FT at $\mathrm{T} 1$ and $\mathrm{T} 2$ and for the $\mathrm{HC}$ group.

FT at T1 FT at T2 HC group

ToM-15 comprehension score (/15)

12

$8^{*}$

$13.3( \pm 3.4)$

ToM-15 false-belief score (/15)

$$
6^{*}
$$

$9^{*}$

$12.7( \pm 1.7)$

RME test Basic emotions score (/10)

7

$4 *$

$6.35( \pm 1.1)$

RME test Complex emotions score (/10)

$$
\text { 8* }
$$

$2 * \#$

$5.7( \pm 1.1)$

SNK Correct detections (/22)

$12 *$

$11 *$

$19.5( \pm 1.9)$

SNK False alarms (/22)

7

3

$3.15( \pm 3.3)$

SNK Correct justifications (/22)

$6^{*}$

$8^{*}$

$19.25( \pm 2.1)$

FBI (/72)

27

16

NA

NA: data not available. ${ }^{*} p<.05$ for the modified $t$ test comparison between FT's and HC scores. \# $p<.05$ for the Procock test comparison between FT's T1 and T2 scores. 


\section{Figures}

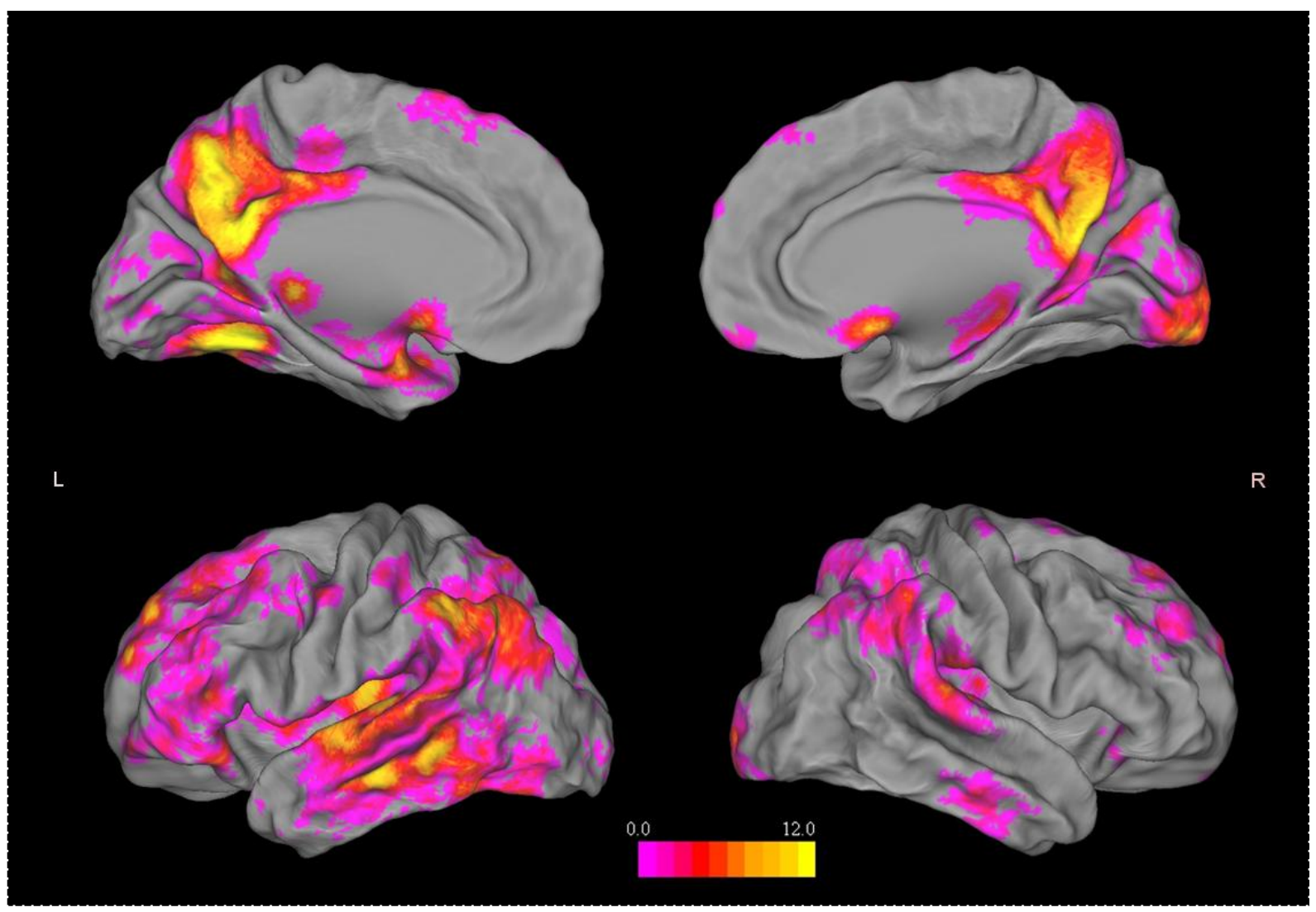

Figure 1. Brain atrophy of FT compared with an HC group at a family wise error corrected threshold of $p=0.05, \mathrm{k}>100$. 


\section{Supplementary data}

\section{Neuropsychological assessment}

The neuropsychological performances of FT for each assessment are summarized in Supplementary Table 1. In January 2014, FT's performance on the free recall component of the Free and Cued Selective Reminding Test (FCSRT) [1] was impaired and improved by cues, but without normalization. Performances on the Trail Making Test (TMT) [2], Wisconsin Card Sorting Test (WCST) [3] and backward digit span of the Wechsler Adult Intelligence Scale [4] pointed to a major dysexecutive syndrome. FT exhibited language disturbances, having difficulty finding her words in the picture-naming task [5] and displaying reduced verbal fluency [6]. Two other assessments were performed in January 2015 and December 2015. The only decrease between them concerns episodic memory.

Supplementary Table 1. Neuropsychological data for FT in January 2014, January 2015 and December 2015

\begin{tabular}{|c|c|c|c|c|}
\hline & $\begin{array}{c}\text { FT } \\
\text { January } 2014\end{array}$ & $\begin{array}{c}\mathrm{FT} \\
\text { January } 2015 \\
\text { T1 } \\
\end{array}$ & $\begin{array}{c}\mathrm{FT} \\
\text { December } 2015 \\
\text { T2 }\end{array}$ & Control Scores \\
\hline MoCA & NA & 18 & 20 & $27.6( \pm 2.4)$ \\
\hline FCSRT free recall (/48) & 18 & NA & 9 & $25^{*}$ \\
\hline FCSRT total recall (/48) & 35 & NA & 14 & $42^{*}$ \\
\hline Doors Test (/24) & NA & 17 & 11 & $16.7( \pm 2.4)$ \\
\hline Digit span forward & 5 & NA & 5 & $7( \pm 2)$ \\
\hline Digit span backward & 3 & NA & 3 & $7( \pm 2)$ \\
\hline TMT B time & 93 & 452 & 250 & $118( \pm 51)$ \\
\hline TMT B error & 0 & 1 & 3 & $1.18( \pm 0.51)$ \\
\hline WCST category & 1 & NA & NA & $3.99( \pm 1.83)$ \\
\hline Categorical Verbal Fluency & 13 & 14 & 9 & $29.7( \pm 8.8)$ \\
\hline Semantic Verbal Fluency & 3 & 9 & 9 & $22.4( \pm 5.5)$ \\
\hline Picture Naming (/80) & 73 & NA & 79 & $75^{\star}$ \\
\hline
\end{tabular}




\section{MRI Method}

\section{MRI Method}

Anatomical MRI was obtained in January 2015, using a Philips Achieva 3.0T MRI scanner. A high-resolution T1-weighted anatomical image was acquired using a three-dimensional fastfield echo sequence (sagittal; repetition time $=20 \mathrm{~ms}$; echo time $=4.6 \mathrm{~ms}$; flip angle $=10^{\circ}$; 180 slices; slice thickness $=1 \mathrm{~mm}$; matrix $=256 \times 256$; field of view $=256 \times 256 \mathrm{~mm}^{2}$ ). Data preprocessing and statistical analyses were performed using voxel-based morphometry implemented in SPM5 (Wellcome Trust Centre for Neuroimaging, London, UK) (for details see [7]). Briefly, this involves a number of fully automated pre-processing steps including spatial normalization into stereotactic (MNI) space, segmentation into grey, white matter and CSF compartments, correction for volume changes induced by spatial normalization, and smoothing with a $12 \mathrm{~mm}$ full width at half maximum isotropic gaussian kernel. To formally assess the extent of atrophy across the whole brain, we compared FT's structural MRI scan with those of 20 matched healthy controls, using a two-sample t test to investigate differences in gray-matter volume. The significance level was set at $p=0.05$, family wise error (FWE) corrected for multiple comparisons, $\mathrm{k}>100$ voxels with a minimum cluster size of 100 voxels. 


\section{Bibliography}

[1] Van der Linden M, Adam S (2004) L'évaluation des troubles de la mémoire: Présentation de quatre tests de mémoire épisodique (avec leur étalonnage), Groupe de Boeck, Bruxelles.

[2] Godefroy O (2008) Fonctions exécutives et pathologies neurologiques et psychiatriques: Évaluation en pratique clinique, Groupe de Boeck, Bruxelles.

[3] Grant DA, Berg E (1948) A behavioral analysis of degree of reinforcement and ease of shifting to new responses in a Weigl-type card-sorting problem. Journal of experimental psychology, 38, 404.

[4] Wechsler D (2008) Wechsler adult intelligence scale-Fourth Edition (WAIS-IV). TX NCS Pearson, San Antonio.

[5] Deloche G, Hannequin D (1997) DO 80: Epreuve de dénomination orale d'images, Editions du Centre de Psychologie Appliquée, Paris.

[6] Cardebat D, Doyon B, Puel M, Goulet P, Joanette Y (1990) Evocation lexicale formelle et sémantique chez des sujets normaux. Performances et dynamiques de production en fonction du sexe, de l'âge et du niveau d'étude. Acta Neurol. Belg. 90, 207-217.

[7] Viard A, Desgranges B, Matuszewski V, Lebreton K, Belliard S, de La Sayette V, Eustache F, Piolino P (2013) Autobiographical memory in semantic dementia: new insights from two patients using fMRI. Neuropsychologia 51, 2620-2632. 